\title{
PENETRAÇÃO DO TRYPANOSOMA CRUZI ATRAVÉS DO PONTO DA PICADA DE TRIATOMÍNEOS
}

\section{V.A. Soares e P.D. Marsden}

Testou-se a eficiência do ponto da picada de triatomineos como via de infecção para o T. cruzi, utilizando-se modelo experimental em camundongos. $A$ infecção, por essa porta de entrada, ocorreu em $24 \%$ dos animais. Considerando-se que os testes foram realizados em condiçōes ótimas, conclui-se que a aquisição da doença de Chagas por esta via não seja comum.

Palavras chaves: Trypanosoma cruzi. Via de infecção. Doença de Chagas.

O ponto da picada de triatomíneos é considerado como uma via provável de infecção pelo $T$. cruzi, porém não existem referências na literatura especializada que comprovem essa hipótese. A possibilidade de infecção por essa via é mais significante quando se considera o hábito dos individuos das principais espécies vetoras em defecar durante, ou logo após, a alimentação ${ }^{7}$, o que asseguraria às formas metacíclicas do $T$. cruzi maiores oportunidades de penetração.

Este trabalho tem como objetivo estudar a capacidade de penetração de formas metacíclicas do T. cruzi através do ponto da picada do Dipetalogaster maximus.

\section{MATERIAĹ E MÉTODOS}

Antes do inicio do experimento propriamente dito, os camundongos a serem utilizados sofreram tratamento da pele na tentativa de evitar a presença de ácaros. O tratamento constava de aplicação local de 2,5 Dioxocarb três vezes por semana. As gaiolas eram desinfetadas com solução formol a $10 \%$ e a maravalha que forrava as gaiolas, autoclavadas por $\mathbf{4 5}$ minutos a $120^{\circ} \mathrm{C}$ e trocadas, também, três vezes por semana.

As fezes de D. maximus infectados com cepa Iuiu de $T$. cruzi, isolada de triatomíneo naturalmente infectado capturado em habitat doméstico na Baixada do Iuiu-Bahia, foram obtidas por dissecção do inseto com retirada do tubo digestivo; o material foi diluido em salina. $O$ número de metacíclicos expostos foi calculado pelo método de Brener ${ }^{2}$.

Uma ninfa de 3 ? $^{\circ}$ estágio de $D$. maximus foi colocada em vidro de boca estreita no interior do qual introduziu-se uma tela plástica que servia de suporte e com a cabeça voltada para boca do vidro tendo seus movimentos restritos ao máximo; o vidro foi então fe-

Núcleo de Medicina Tropical e Nutrição da Universidade de Brasília, 70910 Brasília, Brasil.

Recebido para publicação em 22/5/1985. chado com filo sendo esse procedimento realizado 24 horas antes do experimento para adaptação das ninfas.

Anestesiaram-se, então, 30 camundongos e os triatomíneos foram colocados a sugar na base da cauda desses animais. Observourse o local da introdução da proboscida dos insetos, e a área foi delimitada com tinta. Os triatomíneos foram deixados sugando por 30 minutos aproximadamente. Retirados, então, colocava-se sobre a área marcada duas gotas $(0,05 \mathrm{ml})$ de fezes; deixava-se o material por 45 minutos; findo esse tempo o local era limpo com álcool a $70 \%$ para evitar a possibilidade de contaminação oral.

Utilizaram-se dois grupos controles, um com 18 camundongos que recebeu inóculo intraperitoneal de $0,1 \mathrm{ml}$ do mesmo conteúdo fecal e o outro com 15 animais recebeu o mesmo volume de fezes utilizado no grupo experimental na mesma região da cauda que se apresentava intacta.

A umidade relativa durante o experimento foi de $54 \%$ e a temperatura de $24,5 \circ \mathrm{C}$.

Os animais foram examinados aos 14, 21 e 29 dias após a contaminação fecal, através da observação direta do sangue ao microscópio ${ }^{1}$. Os que se apresentavam negativos foram submetidos a xenodiagnóstico com 10 ninfas de 1. estágio de $D$. maximus e ao teste de desafio com a cepa $Y$ de $T$. cruz $i$ de virulência conhecida, seguindo a técnica de Alvarenga e Marsden ${ }^{1}$.

\section{RESULTADOS}

Os resultados do teste de exposição são apresentados na Tabela 1.

Os resultados comprovam a infecção pela via testada, apesar do número reduzido de animais infectados. A baixa taxa de infecção talvez possa ser explicada pelo fato de que a cauda do camundongo seja altamente queratinizada, já que é conhecido o fato de que dificilmente se observa chagoma de inoculação em mãos e pés, partes queratinizadas do corpo. Mas esse local foi escolhido primeiro pela facilidade em determinar, visualmente, o ponto de introdução da 
Soares VA, Marsden PD. Penetração do Trypanosoma cruzi através do ponto da picada de triatomíneos. Revista da Sociedade Brasileira de Medicina Tropical 19:165-166, Jul-Set, 1986

Tabela 1 - Penetração de formas metacíclicas do Trypanosoma cruzi pelo ponto da picada de Dipetalogaster maximus.

\begin{tabular}{|c|c|c|c|c|c|c|c|}
\hline \multicolumn{2}{|c|}{ Grupo } & $\begin{array}{c}\text { Inóculo } \\
\text { Médio }\left(10^{3}\right)\end{array}$ & $\begin{array}{c}\text { No de } \\
\text { Camundongos } \\
\text { Utilizados }\end{array}$ & $\begin{array}{c}\text { No de } \\
\text { Positivo } \\
\text { Direto }\end{array}$ & $\begin{array}{c}\text { No de } \\
\text { Positivo } \\
\text { Xeno } \\
\text { Diagnosticado }\end{array}$ & $\begin{array}{c}\text { No de } \\
\text { Positivo } \\
\text { Desafio }\end{array}$ & $\begin{array}{c}\text { Total de } \\
\text { Positivos } \\
(\%)\end{array}$ \\
\hline \multicolumn{2}{|c|}{ Teste } & 2,5 & 30 & 7 & - & - & 24 \\
\hline \multirow{2}{*}{ 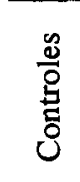 } & $\begin{array}{l}\text { Inóculo } \\
\text { I.P. }\end{array}$ & 5,0 & 18 & $16^{*}$ & - & - & 100 \\
\hline & $\begin{array}{l}\text { Cauda } \\
\text { Íntegra }\end{array}$ & 2,5 & 15 & - & - & - & 0 \\
\hline
\end{tabular}

* Dois animais mortos antes do primeiro exame.

proboscida do inseto, e segundo a temperatura da cauda, segundo foi determinada, é de $29^{\circ} \mathrm{C}$, mais próxima dos valores encontrados para pele humana que é de $33{ }^{\circ} \mathrm{C}^{5}$, do que outros pontos do corpo do camundongo.

\section{DISCUSSÃO}

As vias prováveis de infecção pelo $T$. cruzi foram estudadas por vários autores. A pele integra é considerada como eficiente barreira ${ }^{46}$ sendo pouco provável a infecção através dela. Embora Zeledon et al. ${ }^{8}$ considere que em condições especiais essa seja prejudicada e a infecção, por essa via possa ocorrer.

Através da pele escarificada a infecção chagásica é mais facilmente estabelecida, sendo que a penetração do $T$. cruzi é função do tempo, observando-se um gradiente com maiores taxas de infecção logo após a escarificação e menores a medida em que, com o passar do tempo a pele vai se regenerando 46.

Quando se considera as vias prováveis de infecção conclui-se que a pele escarificada é, possivelmente, a mais eficiente e comum principalmente quando se considera a reação alérgica provocada pela picada de triatomíneos ${ }^{3}$ levando o indivíduo a coçar-se escarificando a pele. Enquanto a lesão causada pela picada do triatomineo é mínima e para que as formas do $T$. cruzi tivessem alguma chance de penetração seria necessário que as fezes fossem depositadas sobre a lesão, como no modelo experimental, o que deve ocorrer raramente tornando essa via de importáncia secundária.

\section{SUMMARY}

We evaluated the efficiency of the site of triatomine bite as the route of infection of $\mathrm{T}$. cruzi using a mouse model. Infection occurred by this portal of entry in $24 \%$ of animals. Considering that these experiments were done under optimal conditions it is concluded that the aquisition of Chagas disease by this route must be uncommon.

Key words: Trypanosoma cruzi infection route. Chagas' disease.

\section{REFERÊNCIAS BIBLIOGRÁFICAS}

1. Alvarenga NJ, Marsden PD. Estudos sobre a persistência de infectividade do $T$. cruzi. I - Efeito da temperatura sobre a infectividade de flagelados da amostra Peru de $T$. cruzi obtidos de fezes de triatomineos. Revista da Sociedade Brasileira de Medicina Tropical, 9: 283-287, 1975.

2. Brener $Z$. Contribuição ao estudo da terapéutica experimental da doença de Chagas. Tese. Faculdade de Farmácia, Universidade Federal de Minas Gerais, Belo Horizonte, 1963.

3. Costa CHN, Weber JN, Gilks GF, Castro C, Marsden PD. Skin reactions to bug bites as a result of xenodiagnosis. Transactions of the Royal Society of Tropical Medicine and Hygiene 75: 405-408, 1981.

4. Marsden PD. Trypanosoma cruzi infections in CFI mice. II - Infections induced by different routes. Annals of Tropical Medicine \& Parasitology 61: 62-67, 1967.

5. Noble WC, Somerville DA. Microbiology if human skin. Vol. 2 W.B. Saunders Co. Ltd. Philadelphia, 1979.

6. Soares VA. Estudo ecológico da relação parasitohospedeiro no momento critico da penetraçào do tegumento de Mus musculus. Tese. Departamento de Biologia Vegetal, Universidade de Brasilia. 1983.

7. Zeledón R, Alvarado R, Jirón LF. Observations on the feeding and defecation patterns of three triatomine species (Hemiptera-Reduviidae). Acta Tropica 34:65-77, 1977.

8. Zeledón R, Trejos M, Chinchilla M. Experimental infections of mice with blood, culture and insect forms of Trypanosoma cruzi by different routes. Parasitology 3: $95-111,1977$. 